\title{
Code-Switching: A Useful Foreign Language Teaching Tool in EFL Classrooms
}

\author{
Aisha Bhatti ${ }^{1}$, Sarimah Shamsudin ${ }^{1} \&$ Seriaznita Binti Mat Said ${ }^{1}$ \\ ${ }^{1}$ Language Academy, Universiti Teknologi Malaysia, Malaysia \\ Correspondence: Sarimah Shamsudin, Language Academy, Universiti Teknologi Malaysia, Malaysia. E-mail: \\ ssarimah.kl@utm.my
}

Received: April 12, 2018 Accepted: May 13, 2018 Online Published: May 15, 2018

doi: 10.5539/elt.v11n6p93 URL: http://doi.org/10.5539/elt.v11n6p93

\begin{abstract}
In every society, language plays a vital role in communicating with each other as it allows speakers to expand their knowledge, deliver their ideas, opinions and feelings in the society. English, as a global language, provides a platform for communication for people who speak the language. Due to the growing trend in linguistic globalisation, bilingualism has become a very common phenomenon in today's world. In bilingual communities all over the world, speakers frequently switch from one language to another to meet communication demands. This phenomenon of alternation between languages is known as code-switching. The present study aims to focus on the teachers' use of code-switching as a language teaching tool in EFL classrooms in Pakistan. It also deals with the functions and types of code-switching in EFL classrooms. Four EFL speaking skill classes were observed, and audio was recorded and transcribed to analyse why and how code-switching was used in the classrooms. The analysis of classroom interaction transcripts revealed that teachers code-switched to maintain discipline, translate new words and build solidarity and intimate relationships with the students before, during and after the lessons. The study found that code-switching from L2 to L1 in the speaking classes did occur although English remained as the main medium of instruction. All the teachers consciously code-switched throughout their lectures. Teachers also code switched to Urdu after the lectures. Three types of code-switching occurred during the EFL classes: tag-switching, intra-sentential code-switching and inter-sentential switching. Hence, code-switching is a useful teaching tool in EFL classrooms to facilitate teaching and learning.
\end{abstract}

Keywords: bilingualism, code switching, sociolinguistics, Foreign Language Teaching Pakistan

\section{Introduction}

\subsection{Interduce the Problem}

In bilingual communities all over the world, where two or more languages co-exist, speakers frequently switch from one language to another in order to meet communication needs. This phenomenon of alternation between two languages is known as code-switching. Bilingualism is considered in itself as a source of creativity in language (Talaat, 2003). In Pakistan, English is taught as a compulsory subject and considered as the medium of instruction from schools up to college or university level. Keeping this view in mind, this study investigated incidences of code-switching among teachers when delivering their lectures in the classrooms. Moreover, at present, sociolinguistics working in classroom discourse has meaningfully lingered on the opportunity to conduct a research in the field based on actual classroom practices. Martin-Jones (1995) asserted that "We need to know how code-switching in bilingual discourse is shaped by the social conditions operating in different types of classrooms and how differing views about the values and purpose of bilingual education are manifested in bilingual discourse practices". Language alternation, particularly code-switching, is defined as the ability of bilinguals to alternate between the languages in their linguistic repertoires (Zentella, 1981). According to Kachru (1986):

"A language may be considered transplanted if it is used by a significant number of speakers in social, cultural and geographical contexts different from the contexts in which it was originally used... a transplanted language is cut off from its traditional roots and begins to function in new surroundings, in new roles and new contexts."

Muysken (2000) used the term 'code switching' to refer to "all cases where lexical items and grammatical features from two languages appear in one sentence". Wardhaugh (2000) believed that 'code' is a natural term as 
compared to terms such as style, creole and pidgin in a language. Besides, it can also be referred to 'any kind of system where two or more persons comply for communication'. Currently, the term 'code-switching' is most commonly used to describe the use of two languages within one conversation or a text (Benson, 2001). Cook (2008) defined code-switching as the process of "going from one language to the other in mid-speech when both speakers knew the same language". Metila (2009) explained that the pedagogical and communicative functions of classroom code-switching justify its use in teaching and learning contexts. An impressive number of studies have been carried out on the use of code-switching in the classrooms.

There has been a debate in literature worldwide on the use of the mother tongue (L1) in a second (L2) or foreign language classroom. To the best of the researchers' knowledge, few studies have investigated the Urdu-English code-switching in a Pakistani educational setting. The code-switching phenomenon (between Urdu and English) could only be observed in TV programmes, talk shows, children's magazines, newspapers and in the field of engineering. Although research on the same issue has been carried out in developed countries, the context was quite different from the one existing in Pakistani classrooms (Gulzar, 2010). With regards to bilinguals, code-switching is a phenomenon that takes place on daily basis. Thus, it is clear that code-switching is a common feature of a bilingual speech, and it refers to the use of two languages in a discourse, conversation or an utterance. This study focused on the use of code-switching as a language tool in speaking skill classrooms with an aim to determine the role of a native language in linguistic development. However, it was observed that the teachers, in spite of having a certain proficiency level of the English language, used code-switching to ensure effective and sufficient learning of the students. Therefore, it aimed to explore the efficiency of code-switching in speaking skill classrooms.

\subsection{Background of the Study}

Though there is a plethora of research concentrating on code-switching, so far, few studies have focussed on code-switching in the context of a speaking skill classroom, especially on the teachers' use of code-switching (between Urdu and English) in bilingual discourse classrooms in Pakistan. Pakistan came into being on 14th August 1947. After its independence, English was transplanted in the sub-continent as stated by (Kachru \& Nelson, 2008), "A language may be considered transplanted if it is used by a significant number of speakers in social, cultural and geographical contexts". Since then English has played a significant role in Pakistan. Although Urdu is the national language, the influence of English continues to be very strong. Gradually, English has become a part of every individual in Pakistan. It is added in core courses in every school and is taught from the kindergarten level until the university level. Nevertheless, most Pakistani students still have problems with the language because of the Grammar-Translation Method that is still prevalent in almost all educational institutions in Pakistan. As a result, many Pakistani students are unable to comprehend English fully or speak the language fluently even after learning the language for a long time. The decline in the level of the English language proficiency among students has brought about the need to tackle the issue. Consequently, teachers began to employ code-switching as a means of providing students with the opportunities to communicate in the language apart from enhancing their understanding. So far, very few studies have investigated code-switching as a teaching tool in speaking skill classrooms at the diploma level in Pakistan.

\subsection{Relevant Scholarship}

Studies in code-switching have evolved over the past three decades. A great number of books have been written, and research have been conducted by linguists interested in studying this language phenomenon (Inuwa, Christopher \& Bakrin, 2014; Gulzar, 2010; Ariffin \& Rafik-Galea, 2009; Bashir, 2015; Woolard, 2004; Deuchar, 2012; \& Makulloluwa, 2013), particularly regarding the social dimensions of code-switching. The approaches discussed in the literature review are meant to gain an in-depth insight. Code-switching is an important phenomenon, and it is regarded as a meaningful speech style used to pull off interactional effects and attain communicative goals. From the sociolinguistics' point of view, it is regarded as a special feature that bilingual and multilingual individual are endowed with. Similarly, Inuwa et al. (2014), explored the use of code-switching among Hausa bilinguals as a conversational strategy manifested effectively to express social meanings influenced mostly by some social variables and morpho-syntactic structures of two languages. Code-switching, the use of two languages in a single discussion, is not a random phenomenon. In fact, it is rather an effective tool. Code-switching serves many functions; for example, it is used to emphasise some points, express empathy and solidarity with students and facilitate understanding by quoting others' words (Gulzar, 2010). Kamisah Ariffin and Shameem Rafik-Galea (2009) conducted a research involving bilingual speakers in Malaysia during a conversation session by showing that the practice of altering/mixing two languages is not only common, but also serves as a communicative strategy. Lin (2013) said that the dramatization of the speech can be expressed through word use or through inventive expressions made by the speakers. According to Bashir (2015), 
code-switching has a variety of purposes in various forms: content delivery, managing discipline, humour and turn the mood. Engku Ibrahim et al. (2013) established the view that code-switching is a part of a conversational strategy that can be used by bilingual speakers effectively to share social meanings that are influenced by social variables and morph syntactic structures of one or more languages. An analysis done by Engku Ibrahim et al. (2013) also showed that the teachers had a positive attitude towards code-switching, and despite the claim that they did not code-switch, they actually did it for pedagogical purposes.

By analysing how code-switching functions as a communicative tool in English as a second language in teacher education in a tertiary institution in Malaysia, Azlan and Narasuman (2013) rectified the systematic and predictive reasons for code-switching in classrooms. They also favoured code-switching which is used to convey ideas in a specific situation and enhance the solidarity among L1 users. Gardner-Chloros (2009) revealed another common reason that motivates the Malaysian-English bilinguals who use code-switching in their conversation i.e. to 'Show Identity'. Gulzar (2014) surveyed socialising functions of code-switching in classroom situations that did not involve bilinguals but foreign language instructions which is different from code-switching in a natural discourse. His analyses showed examples of code-switching related to linguistic insecurity. Barredo (2000) added that code switching is a common phenomenon among Basque-Spanish bilinguals. Brice (1998) suggested that teachers and aides use several overt language strategies such as reiteration and posing vocabulary questions. These strategies reinforce language comprehension, maintain on-task behaviours and encourage the learning of English as a content subject. Similarly, in Turkish setting, there is very latest research that code switching has functional use in both teachers and learners in different private and institutions (Yataganbaba, 2014). Code-switching is an inevitable phenomenon in ESL / EFL classrooms. As Iqbal (2011) shed light on code-switching as a natural, creative and innovative way of communication among bilingual teachers in Pakistan where it is used as a technique for facilitating students in classrooms. Also, Malik in 2014, expresses code-switching as an inspirational strategy for the learners because it provides a 'care-free classroom atmosphere' and ability of students' comprehension. He also asserts code switching also assists students positively.

Therefore, to address this issue, the present study investigated the teachers' use of code-switching in an actual classroom interaction in speaking skill classes (in functional courses). In order to meet this aim, the present study sought to address the following research questions:

1) Do teachers make use of code-switching in speaking skill classrooms (in functional courses)?

2) What is the nature of code-switching used by the teachers?

3) What are the functions and types of code-switching used by the teachers in speaking skill classrooms?

This study is equally beneficial for the teachers and the students as it provides a better understanding on the nature, types and functions of code-switching and its benefits in accelerating language learning. This study would also contribute to the existing literature on code-switching, particularly on the use of code-switching in a speaking classroom. The information gained from this study would also provide insights on the reasons for the use of code-switching in language skill classrooms and its functions as a language tool in speaking skill classrooms. Finally, this study would also act as a platform for future researchers to explore new dimensions of code-switching as an important language tool.

The lectures of four teachers involved were analysed using the theoretical framework of Poplack (1980) categorisation of code-switching. Poplack (1980) identified three types of code-switching: Tag-switching (insertion of a tag phrase from one language into an utterance of another language), Inter-sentential switching (insertion at a clause or sentence boundary) and Intra-sentential switching (insertion within the clause or sentence). Based on the concept of functional specialization by Jakobson (1960) and Halliday et al. (1964), the functions were adopted from Appel and Muysken (1987) and Hoffmann (1991).

\section{Methodology}

Following qualitative research design, the present study aims to explore code switching qualitatively from teachers teaching speaking skills at diploma in the National University of Modern Languages (NUML), Pakistan.

\subsection{Participant and Sampling Procedure of This Study}

For this study, to achieve the objective, four teachers teaching at diploma level were selected from diploma classes. These teachers were selected as all of them had MA and M.Phil. degrees from renowned universities in Pakistan and had more than seven years of teaching experience in teaching EFL. Purposive sampling was used for this specific study. It includes both male and female teachers. 


\subsection{Instrument}

This study used two instruments of data collection: observation and Audiotaped recording in the classroom. Both the teachers and the students in the classrooms were native speakers of Urdu. The students were described as mixed-ability students since they come from different backgrounds and districts in Pakistan with different experiences. An observation checklist was also created for class observations to develop understanding of the use of code switching in the speaking skill classrooms.

\subsection{Data Collection and Analysis}

For collection of data, the observation sheet allowed the researchers to keep a record every time the teachers switched to Urdu.

\section{Observation Checklist/Sheet}

BEFORE THE LECTURE

\begin{tabular}{lllll}
\hline Functions & Teacher A & Teacher B & Teacher C & Teacher D \\
\hline Greeting & $\checkmark$ & $\checkmark$ & $\checkmark$ & $\checkmark$ \\
Chatting & $\checkmark$ & $\checkmark$ & $\checkmark$ & $\checkmark$ \\
Class Instruction & $\checkmark$ & $\checkmark$ & $\checkmark$ & $\checkmark$ \\
Building solidarity and intimate relationship & $\checkmark$ & $\checkmark$ & $\checkmark$ & $\checkmark$ \\
Warm-up-question & $\checkmark$ & $\checkmark$ & $\checkmark$ & $\checkmark$ \\
\hline
\end{tabular}

DURING THE LECTURE

\begin{tabular}{lllll}
\hline Functions & Teacher A & Teacher B & Teacher C & Teacher D \\
\hline Translating new words & $\checkmark$ & $\checkmark$ & $\checkmark$ & $\checkmark$ \\
Explaining difficult ideas & $\checkmark$ & $\checkmark$ & $\checkmark$ & $\checkmark$ \\
Maintaining discipline & $\checkmark$ & $\checkmark$ & $\checkmark$ & $\checkmark$ \\
Making listener attentive & $\checkmark$ & $\checkmark$ & $\checkmark$ & $\checkmark$ \\
Repeating important points & $\checkmark$ & $\checkmark$ & $\checkmark$ & $\checkmark$ \\
Motivating students & $\checkmark$ & $\checkmark$ & $\checkmark$ & $\checkmark$ \\
Quoting examples from personal life & $\checkmark$ & $\checkmark$ & $\checkmark$ & $\checkmark$ \\
Explaining culturally different concepts & $\checkmark$ & $\checkmark$ & $\checkmark$ & $\checkmark$ \\
\hline
\end{tabular}

AFTER THE LECTURE

\begin{tabular}{lllll}
\hline Functions & Teacher A & Teacher B & Teacher C & Teacher D \\
\hline Translating new words & $\checkmark$ & $\checkmark$ & $\checkmark$ & $\checkmark$ \\
Explaining difficult vocabulary & $\checkmark$ & $\checkmark$ & $\checkmark$ & $\checkmark$ \\
Explaining new ideas in different cultures & $\checkmark$ & $\checkmark$ & $\checkmark$ & $\checkmark$ \\
\hline
\end{tabular}

Audio recordings of the teachers' lectures were also transcribed by the researcher to determine the types and functions of code-switching used by the language teachers in the speaking skill classrooms. The audio recordings of the lectures were based on four forty-five minutes lectures conducted by the four different teachers in the speaking skill classrooms.

Data analysis in this study took place in two stages: data analysis through audiotaped recordings according to the three types of code switching suggested by Poplack (1980): Tag-switching (exclamations, tags, discourse markers, adverbials, terms of address etc.), Inter-sentential switching (insertion of a phrase or a clause between sentences) and Intra-sentential switching (insertion of words, phrases or clauses in the middle of a sentence). And data analysis according to the functions of code-switching by Appel and Muysken (1987) and Hoffmann (1991). The qualitative descriptive analysis was done to analyse the data. 


\subsubsection{Tag-Switching}

Close observation of all the extracts by the four teachers revealed that the most commonly used tags were "theek hai!" and "theekh", and "Gee" was used as a question with multiple meanings including "OK! is it clear/ clear! alright? any confusion! yes? Agree? Right? etc." All these meanings have the same purposes i.e. to express concern for the students and ask them again and again if they had any difficulty in understanding the concept being discussed. Moreover, some tags such as "acha" and "gee haan" were just habits exhibited by the teachers. Many of them also displayed the habit of saying "beta" to their students. These expressions enhanced the teacher-student relationship, and they helped learners feel close to their teachers. Interestingly, these tags did not serve any special educational functions. They were rather used for social functions with more focus on building solidarity and intimate relationship between the teachers and the learners in the speaking skill classroom environment.

\subsubsection{Inter-Sentential Switching}

A close analysis of the extracts revealed that most of the inter-sentential switches had an explanatory nature. Such as shown in this example, make a mind map of what have you learnt from your life so far? Ap ne ab tak apni zindagi se kya seekha hai? (What lessons have you learnt from your life?) Now the topic is not given. A question is given. Similarly, in another extract; What is criticism basically? Criticism kokesy define kerty hain ap? Ap ko kaha jaye kisi cheez ko criticize karein, ap kesay karein ge? (How to define the term "criticism? How would you criticize something?) you will look at its positive and negative points both. Not only negative points, but positive too. From the above examples, the teachers switched to Urdu in the speaking skill classrooms when they felt that the concept they were explaining was a bit difficult and needed a clear explanation for the learners to understand. Another function of these inter-sentential switches appeared to be as an attention focusing device. In most cases, it was observed that when the teachers were explaining difficult concepts and wanted to get their students' attention, they moved from low tone to high tone, along with the change of code which served dual purposes: simplifying the explanation and making students attentive. The analysis of these switches also clearly indicated that these switches had pure educational effects, with the main goal to facilitate student learning.

\subsubsection{Intra-Sentential Switching}

A closer analysis of the extracts revealed that the intra-sentential switches were used for educational purposes. This technique is useful to enable students to associate concepts and definitions explained in a foreign language with that of their mother tongue. These are examples of the extracts: Ager aap foran se start ker dein aur ap kahein keh (If you start it quickly and say that) I was so composed, I was so organized in my thoughts, tou ye hap ki free writing consider nahi ho gi (it will not be considered your free writing); Just take your time and see all the options that you can make out for that sentence and choose the best one jo ap ko lagta hai keh sahi hai, logically sentence ko connect ker raha hain. (that you feel is correct and logically connecting the sentence). Therefore, the main purpose of this switch appeared to be the association of the subject matter on the part of the learners.

\subsubsection{Functions of Code Switching}

Heigham and Crocker (2009) believed that "observation is the conscious noticing and detailed examination of participants' behaviour in a naturalistic setting" (Heigham \& Crocker, 2009, p. 166). They further categorised a researcher into four: complete participant, participant as observer, observer as participant, and complete observer (Heigham \& Crocker, 2009, p. 167).

The functions of code-switching were then further divided into two main categories:

\subsubsection{Methodological Functions}

Methodological functions include all the language-related functions of code-switching by the teachers to teach the target language, i.e. translation, explanation of difficult concepts and other communicative strategies between the teachers and the learners.

\subsubsection{Social Functions}

On the other hand, social functions include disciplining the students, giving them instructions about classroom activities or dealing with the emotional side of the students' personality. These functions are not directly related to target language teaching. 


\section{Results}

\section{Teacher A}

Teacher A used the words "bachay" and "jee" habitually. These expressions manifested her friendly and kind nature which gave a relaxing effect on the students. All the students felt at home in her class, and they felt closer to their teacher. The teacher gave a lecture on "Eating Manners", and she code-switched frequently whenever she felt that there were some difficult or important points to explain. For example, while explaining the kinds of dishes, she used so many names to clarify the concepts. She used "chawal kari", "Baisan", "Kurry", "Lasi Pakoray". Teacher A also code-switched to create fun to make the class environment more relaxed and friendly. For example, she asked the students to tell her the English translation for "ChupChup", which means "munching" or eating quickly. While explaining the technique of "Mind-Mapping", the teacher quoted an example from the Chinese culture and code-switched. Therefore, although she used an example taken from the Chinese culture, she managed to convey a clear message for the students. The teacher also had different classroom activities during her lecture. To maintain discipline in her class, she said "Batain na karain" which means "Please" or "Listen carefully", "No discussion!" or "Please don't discuss anything!" In short, Teacher A frequently code-switched and based on the students' expressions, it appeared that they comprehended the ideas and enjoyed the lecture completely.

\section{Teacher $B$}

Teacher B gave a lecture on "Presentation Skills". She explained important points in Urdu during her lecture about giving a presentation. She explained all the parts of a presentation in details, including the preparation of power-point slides, use of microphones and speakers, time-management, dress code and gesticulation. During her lecture, she gave two examples involving her previous students who committed mistakes before and during their presentations. She explained, "Last time it happened...one of the students' group in another section came to me at the time of their presentation and said, 'Teacher wo jo hamari documentary thi, who amarye ik friend ke pass thi, wo kal se apny gaon gae hua haia ur raastey mei pata nai kya hogya hai, roads block hai wo nahi aa saka' (teacher, our documentary is with one of our friends who has gone to his village, and now he's unable to come because the roads are blocked). The teacher replied, "You were six members! Nobody had the copy of the documentary?" He said, "No", so I said "All right". For the documentary, they simply got a zero, and whatever they presented "jo un ki presentation thi us mein mei ne unhein marks diye jo documentary unhon ne mujhey nahi di khai" (I gave them marks for their presentation, and the documentary that I didn't watch, I didn't give any marks to them). Fine! 'kyon keh last time peap ka koi excuse accept nahi hoga' (because I won't accept any excuse by you at the eleventh hour), and I gave you this assignment ...it's been one month now. 'Theek hai'? (clear!) I gave you enough time (L4-16). Talking about the audience, she said, "Your audience is the students plus your teacher. Kuch students atey hain who mujhey hi dekhna shuru ker detey hain ur mujhey hi dekhtey huey presentation khatam ker detey hein (Some students start [their] presentation while looking at me, and end it the same way). You must have eye contact with all the people including your teacher, ok?" (L73-76). In the end, the teacher announced their final project and presentation, and again, she code-switched as it was a piece of important information, and she wanted every student to listen to and understand whatever that she was elaborating. Overall, the teacher used code-switching for class instructions, as Malik (2014), confirmed that $64.6 \%$ students like the way of teaching if the teacher code switch for the giving questions instructions while using this strategy of code switching students to codeswitching warm-up questions, explaining difficult ideas, maintaining discipline and listeners' attention, and when repeating or changing topics. It was clear that her purpose was to facilitate student learning. The students' excitement during the lecture indicated that she had used code-switching as a teaching aid quite successfully.

\section{Teacher C}

The third teacher delivered a lecture on "Eid Celebrations". She used Urdu quite frequently, because there was no equivalent in English language for cultural celebrations in Pakistan. Gumperz and Hernandez-Chavez (1971), analyzed that English saved to interduce new word or information While Spanish provide stylistic embroidery for the speaker's intent. The teacher $\mathrm{C}$ did not only to explained the difficult terms in the different cultures, but also for class instructions and warm-up questions. It was observed that her code-switching at the very beginning of her lecture made the students feel relaxed and attentive. The teacher repeated many points in Urdu just to make sure that all the students understand the vocabulary. The teacher also code-switched when giving details about the types of dresses. Over all, the teacher was in favor of code-switching and was very comfortable in doing so whenever she felt it was necessary during the lecture. 


\section{Teacher D}

Compared to other teachers, Teacher D who delivered a lecture on "cultural foods", switched code less during her lecture. Instead of lecturing, she had informal chats with students as she explained difficult points about foods in different cultures. For example, she explained the difference between cultural foods and fast food very clearly by giving the examples of 'makaiy ki roti and chappati' which are not available in the European culture. Although this teacher used less code-switching as compared to other teachers, it was obvious that she was in favour of the use of L1 during her lectures; thus, she felt comfortable to code switch freely whenever she felt it was necessary to aide students' understanding. In general, it could be implied that the teacher believed that code-switching is a universal and inevitable practice in the speaking classrooms.

\section{Discussions}

In summary, the present study has demonstrated that the recorded lectures of the four teachers highlighted the occurrences of code-switching from L2 to L1 in the speaking skill classrooms although English remained as the main medium of instruction. The analysis illustrated three types of code-switching (tag-switching, inter-sentential and intra-sentential switching) mentioned by Pollack (1980) were found to be used by all the teachers during the lectures. However, the dominant patterns found during the observation of the lectures were Tag-Switching and Intra-sentential code-switching. It was also observed that the code-switching during the speaking classrooms had served different functions before, during and after the lecture. These functions included greetings, chatting, building solidarity and intimate relationship, and accelerating the warm-up session before the lectures formally started. During the lectures, the teachers switched code when translating new words, explaining difficult concepts, maintaining discipline and getting attention of the listeners. Sometimes, the teachers used L1 to repeat important points and explain the different concepts practised in different cultures. Almost all the teachers were found to give counselling to the students in Urdu after their lectures. Thus, it can be concluded that all the teachers in this study used Urdu for effective communication in accord with the findings of Camilleri (2001), she found that the teachers used code switching as a source of communication which functions to give explanation, introduce new topics or give extra comments. The observation revealed that Urdu was used by the teachers when they felt that English-only strategy failed to work. Hence, code-switching plays a supportive and facilitating role in the speaking classrooms.

The study proves that code-switching is inevitable and necessary in speaking skill classrooms in the Pakistani context as the students lack competence in the English language. As Zentilla (1981) expresses that" it seems premature to ban code switching from the classroom" He also argued "nor is it helpful to say it should be incorporated into the classroom mechanistic way". In this situation, code-switching proves to be a facilitating factor and a time-saving strategy.

Although language policy in Pakistan favours the use of English as the medium of instruction, code-switching occurs at all levels even in speaking skill classrooms. Although the teachers who practise code-switching are well aware of the violation of the language policy, they believe that code-switching between English and Urdu in the speaking classrooms facilitates those learners who are not proficient enough in English. In short, the data collected from the teachers suggest a positive use of code-switching. It implies that code-switching should never be considered as a sign of a teacher's incompetence in the target language; instead, it is viewed as an effective language teaching tool employed by the teachers in the speaking skill classrooms. Lawrence (1999) focused on the point that code switching between Afrikan and English should not be considered as an inadequacy rather it's an instrument for effective communication. The findings of this study also clearly indicate that the teachers perceive code-switching in the speaking skill classroom positively. Most of the teachers code-switched to Urdu in the speaking skill classes (functional courses), and this shows that there is a notable relationship between the teachers' code-switching and learners' learning success. Code-switching also plays a significant role in enhancing the learners' psychological state, so the teachers code-switched during their lectures in the speaking skill classrooms to achieve different academic and social functions. As a conclusion, code-switching should be continued as a medium of language teaching and not be regarded as a mere teaching technique.

The results of this study are in line with those reported by previous research. Evidence has shown that code-switching has taken place in the teaching of grammar, in explaining difficult concepts and in repeating instructions to those who have difficulty in understanding them in the target language. There is a still need to improve understanding on the phenomenon of code-switching in multilingual societies as in Pakistan in order to have new insights in this area of studies can lead to a better understanding of the process of code-switching. 


\section{Conclusion}

Based on the findings of the study, the teacher participants treated code-switching as a language teaching tool, and observations showed prevalent use of all three types of code-switching: Tag switching, Inter-sentential switching and Intra-sentential switching. The qualitative study employed observation of the teachers' lecture sessions as well as transcriptions of audio recordings of the lectures. Findings revealed that the teachers code-switched to maintain discipline, translate new words and build solidarity and intimate relationships with the students. Code-switching took place in different situations in the teaching of grammar, in explaining difficult concepts and in repeating instructions to those who had difficulty in understanding in the target language. Despite being well-aware of the language policy, the participants continued to code-switch to Urdu in the speaking classrooms as the students were not proficient enough in English. It is thus recommended that further research is carried out to explore code-switching in depth.

\section{Acknowledgements}

The researcher gratefully acknowledges the teachers who provided the relevant knowledge and expresses sincere thanks to the participants who participated courteously in this study.

\section{References}

Appel, R., \& Muysken, P. (1987). Language contact and bilingualism. London: Arnold.

Ariffin, Rafik-Galea. (2009). Code-switching as a communication device in conversation. (n.d.).

Azlan, Mastura, N., Ismail, N., \& Narasuman, S. (2013). The Role of Code-Switching as a Communicative Tool in an ESL Teacher Education Classroom. Procedia - Social and Behavioral Sciences, 90, 458-467. https://doi.org/10.1016/j.sbspro.2013.07.115

Barredo, I. M. (2000). Pragmatic functions of code-switching among basque-spanish bilinguals. Actas Do I Simposio Internacional Sobre O Bilinguismo, 217, 528-541.

Brice, A., Mastin, M., \& Perkins, C. (1998). English, Spanish, and Code-Switching Use in the ESL Classroom: An Ethnographic Study. Communication Disorders Quarterly, 19(2), 11-20. https://doi.org/10.1177/152574019801900202

Bashir, A., \& Author, C. (2015). The Functions of Code Switching in ESL Classroom Discourse. Journal of Literature, Languages and Linguistics, 6, 6-9.

Benson, E. (2001). The Neglected Early History of Codeswitching Research in the United States. Language \& Communication, 21, 23-36. https://doi.org/10.1016/S0271-5309(00)00012-4

Camilleri, A. G. (2001). Language values and identities: codeswitching in secondary classrooms in Malta. In M. Heller, \& M. Martin-Jones (Eds.), Voices of Authority: Educational and Linguistic Difference (pp. 213-234). Connecticut: Ablex Publishing.

Cook V. (2000). Second language learning and language teaching. Beijing: Foreign Language Teaching and Research Press and Edward Arnold (Publishers) Limited.

Deuchar, M. (2012). Code Switching. The Encyclopedia of Applied Linguistics. https://doi.org/10.1002/9781405198431.wbeal0142

Engku, H. E. I., Mohamed, I. A. S., \& Najwa, T. A. (2013). Code-Switching in English as a Foreign Language Classroom: Teachers' Attitudes. English Language Teaching, 6(7), 139-150.

Gardner-Chloros, Penelope. (2009). Sociolinguistic Factors in Code-Switching. The Handbook on Code-Switching, 97-113. https://doi.org/10.1017/CBO9780511576331.007

Gulzar, M. A. (2010). Code-switching: Awareness about Its Utility in Bilingual Classrooms. Bulletin of Education and Research, 32(2), 23-44.

Gumperz, J. J. (1972). Bilingualism, bidialectalism and classroom interaction. In J. J. Gumperz (Ed.), Language in social groups (pp. 311-391). Stanford, Stanford University Press.

Heigham, J., \& Croker, R. (2009). Qualitative Research in Applied Linguistics, Practical Introduction.

Inuwa, Y. N., Christopher, A. A., \& Bakrin, H. B. (2014). Factors Motivating Code Switching Within the Social Contact of Hausa Bilinguals. IOSR Journal Of Humanities And Social Science, 19(3), 43-49. https://doi.org/10.9790/0837-19354349

Iqbal, L. (2011). Linguistic Features of Code-Switching: A Study of Urdu / English Bilingual Teachers' 
Classroom Interactions. International Journal of Humanities and Social Science, 1(14), 243-244.

Kachru, B. B. (1986). The Alchemy of English: the Spread, Functions, and Models of Non-native English.

Lawrence, D. (1999). Codewisseling:Engels in Afrikaans-en instrument tot effektiewe kommunikasie. Journal language teaching, 33(3), 265-274.

Lin, A. (2013). Title Classroom code-switching: Three decades of research Author (s) Lin, A Citation Applied Linguistics Review, 4(1), 195-218

Metila, R. A. (2009). Decoding the Switch: The functions of codeswitching in the classroom. Education Quarterly, 67(1), 44-61.

Muhammad, S. G. (2014). Teachers' Code-Switching in a Content-Focused English as a Second Language (ESL) Classroom: Patterns and Functions. International Journal of Linguistics, 6(4), 130-153.

Muysken, P. (2000). Bilingual Speech. A Typology of Code-Mixing. Cambridge: CUP.

Poplack, S. (1980). Sometimes I'll start a sentence in Spanish y termino en espa??ol: Toward a typology of codeswitching. Linguistics, 18(7-8), 581-618.

Wardhaugh. (2000). An introduction to sociolinguistics. Beijing: Foreign language teaching and Research Press.

Woolard, K. A. (2004). Codeswitching. A Companion to Linguistic Anthropology. Language, 83(4), 914-915. https://doi.org/10.1353/lan.2008.0041

Yataganbaba, E. (2014). An investigation of code switching into EFL young language learner classrooms (Master's thesis).

Zentella, A. C. (1981). Tabien, you could answer me en cualquier idioma: Puerto Recan Code-switching in bilingual classrooms. In R. P. Duran (Ed.), Latino Language and Communicative Behaviour (pp. 95-107). Norwood, New Jersey: ABLEX Publishing Corporation.

\section{Copyrights}

Copyright for this article is retained by the author(s), with first publication rights granted to the journal.

This is an open-access article distributed under the terms and conditions of the Creative Commons Attribution license (http://creativecommons.org/licenses/by/4.0/). 